\title{
The Evaluation of the Effects of Temozolomide on MGMT Gene Expression in MCF-7 and SKBR3 Human Breast Cancer Cell Lines
}

\author{
Onur Eroğlu' ${ }^{1,2^{*}}$, Büşra Sevim ${ }^{1}$ \\ ${ }^{1}$ Department of Molecular Biologyand Genetics, Faculty of Art and Science, Bilecik Seyh Edebali University, Bilecik, Turkey \\ ${ }^{2}$ Biotechnology Research and Application Center, Bilecik Seyh Edebali University, Bilecik, Turkey \\ Email: *onur.eroglu@bilecik.edu.tr
}

How to cite this paper: Eroğlu, O. and Sevim, B. (2019) The Evaluation of the Effects of Temozolomide on MGMT Gene Expression in MCF-7 and SKBR3 Human Breast Cancer Cell Lines. Journal of Cancer Therapy, 10, 215-228.

https://doi.org/10.4236/jct.2019.103018

Received: February 15, 2019

Accepted: March 8, 2019

Published: March 11, 2019

Copyright ( 2019 by author(s) and Scientific Research Publishing Inc. This work is licensed under the Creative Commons Attribution International License (CC BY 4.0).

http://creativecommons.org/licenses/by/4.0/

\begin{abstract}
Background and Aim: In this study, it was aimed to examine the cytotoxic effect of temozolomide (TMZ) treatment, on MCF-7 and SKBR3 cell lines, to study the methylation levels of MGMT gene expression and gene promoter region. Methods: The MTT test was performed to determine the effective dose of TMZ. The time-dependent cell survival test was performed after the $\mathrm{IC}_{50}$ value was found. Western blotting was performed to determine MGMT gene expression levels. High Resolution Melting (HRM) technique was used to determine the methylation levels of MGMT gene promoter region. Results: TMZ has been shown to have a high cytotoxic effect on SKBR3 cell line and low cytotoxicity on MCF-7. When MGMT expression levels before and after TMZ treatment were observed by western blotting, the gene expression levels of TMZ treatment were shown to decrease in both cell lines. It was observed that MGMT gene promoter region was hypermethylated in two cell lines, and that the application of TMZ further increased the methylation levels in the promoter region. Conclusions: It was seen that TMZ could be used as a single agent in SKBR-3 cell line. With this study on breast cancer, it is expected that temozolomide treatment will lead future in vitro and in vivo studies for breast cancer.
\end{abstract}

\section{Keywords}

Breast Cancer, Temozolomide, MGMT, MCF-7, SKBR3, HRM

\section{Introduction}

Breast cancer is one of the most common cancers worldwide affecting women. Breast cancer, together with lung and colorectal cancers, accounts for $46 \%$ of all 
cancer-related deaths in women and nearly half a million women die each year from this disease [1] [2]. It is a cancer type that still has the highest mortality rate among women, after lung cancer, in spite of a certain improvement in survival rates since the 1990s. In 2017, it is expected that around 63,410 new breast cancer cases will be diagnosed. It is also predicted that by $2017,30 \%$ of all cancer diagnoses will consist of breast cancer cases in women [3].

There are different risk factors that are effective in breast cancer formation. These risk factors vary widely, such as age, hereditary factors, epigenetics, socioeconomic level, environmental factors and personal habits (smoking and alcohol use) [4]. One of these factors, the research on epigenetics, showed that epigenetic regulation of gene expression had a critical role in normal development and cell function [5]. DNA methylation is one of the epigenetically controlled modifications. DNA methylation is divided into hypomethylation and hypermethylation. Hypomethylation leads to an increase in expression levels by the demethylation of methylated mature genes in DNA. Expression of normally silenced genes, like HRAS and other oncogenes, can induce abnormal cell activity and tumorigenesis [6]. Hypermethylation, which is the opposite of this mechanism, occurs when a gene is silenced by methylation of $\mathrm{CpG}$ islands located in the regulator or promoter regions. The gene with the highest hypermethylation activity in breast cancer is BRCA1 gene [6]. Hypermethylation of more than 100 genes has been reported in primary breast cancers or breast cancer cell lines, except for BRCA1 [7]. These methylene genes have critical roles in mechanisms such as tumour suppression, regulation of cell cycle, angiogenesis, tumorigenesis, tissue invasion and metastasis [6].

A gene whose expression and regulation are controlled by the methylation of $\mathrm{CpG}$ islands in the promoter region and which plays a crucial role in carcinogenesis is MGMT gene, also known as $\mathrm{O}^{6}$-methylguanine methyl transferase [8]. $\mathrm{O}^{6}$-methylguanine methyltransferase (MGMT) is a DNA repair enzyme that inhibits mutations that may occur in guanine by transferring guanine-linked promutagenic alkyl groups to its cysteine acceptor region [9]. In cells without MGMT, $\mathrm{O}^{6}$-methylguanine $\left(\mathrm{O}^{6} \mathrm{MeG}\right)$ is not repairable and therefore these cells are more sensitive to the mutagenic and cytotoxic effects of alkylating agents [9]. If $\mathrm{O}^{6} \mathrm{MeG}$ is not repaired by MGMT, conditions such as chromosomal anomalies and point mutations can be observed [9]. Apoptosis is induced through $\mathrm{O}^{6} \mathrm{MeG}$, Fas and p53-dependent pathways [9].

The methylation of MGMT promoter region is a highly advantageous situation for treatment with DNA methylating/alkylating agents [10]. DNA alkylating agents are the earliest and most commonly used drugs as anticancer drugs. Although the mechanism of action of most alkylating agents is similar, they differ in terms of clinical effects. These agents act directly on DNA, causing crosslinking and double-stranded DNA fragmentations, and cause false base pairings on DNA and inhibition of cell division, leading to cell death [11]. Epigenetic silencing of MGMT gene is associated with long-term survival in chemotherapy treatment with alkylating agents such as carmustine and TMZ [12]. 
Temozolomide is a second-generation imidatetrazine lipophilic prodrug with very effective results when used in glioblastoma multiforme (GBM) patients together with radiotherapy treatment [13]. This agent, taken orally, is rapidly absorbed and its bioavailability is close to $100 \%$ [13]. The duration of exposure to TMZ decreases MGMT level. In a randomized study by the European Organization for Research and Treatment of Cancer (EORTC) and the National Cancer Institute of Canada (NCIC), the combined use of radiotherapy and TMZ in 573 patients with newly diagnosed GBM showed a prolonged survival in patients [14].

In this study, due to the relationship of MGMT with estrogen receptor- $\alpha$ (ER$\alpha$ ) and tumor protein (TP53) [15], SKBR3 (with ER- $\alpha(-)$ and TP53 homozygous mutant character) and MCF-7 (with ER- $\alpha(+)$ and TP53 wild type character) human breast cancer cell lines were used. The aim of the study is to observe the results of the cytotoxic effects of TMZ treatment on human breast cancer cell lines with different characteristics and to examine the methylation of MGMT promoter regions. The use of TMZ as a single agent in breast cancer is the first in terms of the literature.

\section{Materials and Methods}

\subsection{Cell Lines and Cell Culture}

MCF-7 and SKBR3 breast cancer cell lines were provided by Istanbul University Experimental Medicine Research Institute, Prof. Dr. Oğuz ÖZTÜRK. MCF-7 cell lines were grown in RPMI-1640 medium containing 10\% heat-inactivated fetal bovine serum (FBS), $2 \mathrm{mM}$ L-glutamine, $100 \mu \mathrm{g} / \mathrm{ml}$ penicillin/streptomycin at $37^{\circ} \mathrm{C}$ and in (Memmert) T25 flasks with 5\% $\mathrm{CO}_{2}$ incubators. For SKBR3, Dulbecco's Modified Eagle's Medium (DMEM) (GIBCO) was used as a medium.

\subsection{MTT Assay}

It was performed using TMZ to measure dose-dependent survival in MCF-7 and SKBR3 cell lines. Temozolomide (Sigma-Aldrich) was applied to MCF-7 and SKBR3 cell lines at different dose intervals $(0-500 \mu \mathrm{M})$. For both cell lines, $7 \times$ $10^{3}$ cells were seeded in 96-well plate (SARSTEDT) as $100 \mu \mathrm{L}$ per well. After growing the cells in the incubator overnight, the dose range was determined and the drugs prepared in the tubes were distributed to the relevant wells as $100 \mu \mathrm{l}$ per each. Plates were kept overnight in the incubator. In the dark environment, $10 \mu \mathrm{l}$ MTT Reagent was added to each well, and after incubation for 4 hours, 570 and $650 \mathrm{~nm}$ absorbance values were measured by ELISA.

\subsection{Trypan Blue Assay}

From the cultured cells, the most suitable one in terms of morphology and density was selected and trypsinization process was performed. Cell seeding was carried out in 6-well plates (SARSTEDT) so as to place $1 \times 10^{6}$ cells per well. Then they were kept in the incubator at $37^{\circ} \mathrm{C}$ overnight. The media of the posi- 
tive control wells were renewed, the wells to be added negative control (DMSO) and medication were renewed after their media were prepared. Then they were kept in the incubator at $37^{\circ} \mathrm{C}$ overnight. Media of control groups were discarded. Media in DMSO and drug containing wells were transferred to $2 \mathrm{ml}$ eppendorf tubes and centrifuged at $2000 \mathrm{rpm}$ for 5 minutes at room temperature $\left(26^{\circ} \mathrm{C}\right.$ $27^{\circ} \mathrm{C}$ ) (Thermo Scientific-MICROCL 21R). The drained wells were washed with $1 \mathrm{ml}$ of $1 \mathrm{xPBS}$ and trypsinization process was performed. $1 \mathrm{ml}$ of media was added to the wells and the whole solution was transferred to eppendorf tubes. The tubes were centrifuged at $2000 \mathrm{rpm}$ for 5 minutes at room temperature $\left(26^{\circ} \mathrm{C}-27^{\circ} \mathrm{C}\right.$ ). Supernatant was removed. $50 \mu \mathrm{l} 0.4 \%$ (w/v) Trypan Blue and 50 $\mu \mathrm{l}$ media (RPMI-1640 for MCF-7, DMEM for SKBR3) were added in a ratio of 1:1. $10 \mu \mathrm{l}$ sample was taken and loaded into Neubauer hemocytometer and viable cell counts were performed on an invert microscope (Nikon Eclipse TS100). Each step after the drug application was repeated at 24, 48, 72 and 96 hours. The results were tabled and evaluated.

\subsection{Western Blot Assay}

Cells were harvested by washing with PBS and lysed for performing protein isolation. The concentration of the isolated proteins was determined using Bradford Reagent (Bio-Rad). 12\% SDS-PAGE electrophoresis was performed with 25 $\mu \mathrm{g}$ protein sample. After the electrophoresis, the proteins were transferred to nitrocellulose membranes. These membranes were blocked in $5 \%(\mathrm{w} / \mathrm{v})$ powdered milk in PBS containing $0.1 \%$ Tween 20 at room temperature and incubated overnight at $4^{\circ} \mathrm{C}$ with primary antibodies (MGMT 1:200, $\beta$-actin 1:10,000 dilution). Membranes were washed and treated with secondary antibody. Proteins were visualized using the ECL system in the imaging device. MGMT expression was normalized using the $\beta$-actin level.

\subsection{DNA Isolation and Sodium Bisulfite Modification}

Manual DNA isolation was performed from a control group and from a drug-treated group for MCF-7 cell line. Two groups, one control group and one drug-treated group, were also formed for SKBR3 cell line and manual DNA isolation was performed from both groups. For this, a DNA isolation protocol was applied from mammalian cells. In this study, Zymo EZ DNA Methylation-Gold ${ }^{\mathrm{m}}$ Kit was used for the bisulfite modification. In accordance with the protocol of the commercial company suitable for kit, DNA samples obtained from MCF-7 and SKBR3 cell lines have been modified.

\subsection{High Resolution MGMT Promoter Methylation Assay}

Appropriate PCR reactions and conditions were prepared with bisulfite-modified DNA samples (control group without drug treatment and DNA samples isolated from MCF-7 and SKBR3 cell line drug-treated for 24 hours). PCR reaction was set up as $20 \mu \mathrm{l}$ in total $(10 \mu \mathrm{l} 2 \times$ Brilliant HRM Ultra-Fast Loci master mix, $5 \mu \mathrm{l}$ 
DNA sample, $0.5 \mu \mathrm{l}$ forward primer, $0.5 \mu \mathrm{l}$ reverse primer, $4 \mu \mathrm{l}$ nuclease-free water) (Primer sequences used are given in Table 1). Samples were placed on 96-well plate. With AriaMx Real-Time PCR System device (Agilent Technologies-Aria Mx Real Time PCR Systems), the hotstart was initiated at $95^{\circ} \mathrm{C}$ for 3 minutes, amplification occurred in 50 cycles for 4 seconds at $95^{\circ} \mathrm{C}$ and $30 \mathrm{sec}$ onds at $60^{\circ} \mathrm{C}$; and $\mathrm{PCR}$ reaction was performed with the high-resolution melting in 1 cycle for 30 seconds at $95^{\circ} \mathrm{C}, 30$ seconds at $60^{\circ} \mathrm{C}$ and 30 seconds at $95^{\circ} \mathrm{C}$.

\subsection{Statistical Analysis}

Methylation levels of genes have been identified by comparing the peaks of controls and the celllines. The analyses were carried out with SPSS version 22.0 (SPSS Inc., Chicago, IL). All the experiments were performed in triplicates.

\section{Results}

\subsection{MTT Assay}

\subsubsection{MTT Test Findings after TMZ Application in MCF-7 Cell Line}

In this method, a graphic was created by applying the potential effect TMZ on the cells with cell viability at $0-500 \mu \mathrm{M}$ dose concentrations. As a result of the values found, $\mathrm{IC}_{50}$ value, which is $40 \mu \mathrm{M}$ for $\mathrm{TMZ}$ was found to reduce cell viability to $49 \%$. Test findings are shown in Figure 1(a).

\subsubsection{MTT Findings after TMZ Application in SKBR3 Cell Line}

In this test, the effect of TMZ on dose-dependent cell viability was examined by applying a dose range of $0-500 \mu \mathrm{M}$. As a result of absorbance values measured at a wavelength of $650 \mathrm{~nm}$, it was determined that the $\mathrm{IC}_{50}$ value for $\mathrm{TMZ}$ was 50 $\mu \mathrm{M}$. The findings are shown in Figure $1(\mathrm{~b})$.

\subsection{Trypan Blue Assay}

\subsubsection{Time-Dependent Survival Test Findings in MCF-7 Cell Line}

In order to evaluate the cytotoxic effect of TMZ on MCF-7 cell line, a drug concentration of $40 \mu \mathrm{M}$ was treated to MCF-7 cells at 24, 48, 72 and 96-hour intervals and its effect on cell viability was observed. As seen in Figure 2(a), $40 \mu \mathrm{M}$ concentration of TMZ significantly reduced cell viability by $53.5 \%$ significantly compared to the control group at 24th hour on MCF-7 breast cancer cell line. It

Table 1. Primer sequences used in high resolution MGMT promoter methylation assay.

\begin{tabular}{|c|c|}
\hline $\begin{array}{l}\text { MGMT Methylated } \\
\text { Forward Primer }\end{array}$ & 5’-TTT-CGA-CGT-TCG-TAG-GTT-TTC-GC-3' \\
\hline $\begin{array}{l}\text { MGMT Unmethylated } \\
\text { Forward Primer }\end{array}$ & 5'-TTT-GTG-TTT-TGA-TGT-TTG-TAG-GTTTTT-GT-3' \\
\hline $\begin{array}{l}\text { MGMT Methylated } \\
\text { Reverse Primer }\end{array}$ & 5'-GCA-CTC-TTC-CGA-AAA-CGA-AAC-G-3' \\
\hline $\begin{array}{l}\text { MGMT Unmethylated } \\
\text { Reverse Primer }\end{array}$ & 5'-AAC-TCC-ACA-CTC-TTC-CAA-AAACAA-AAC-A-3' \\
\hline
\end{tabular}




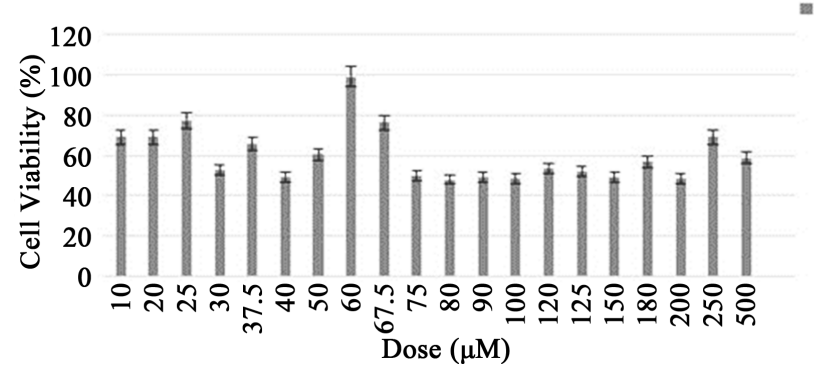

MCF-7

(a)

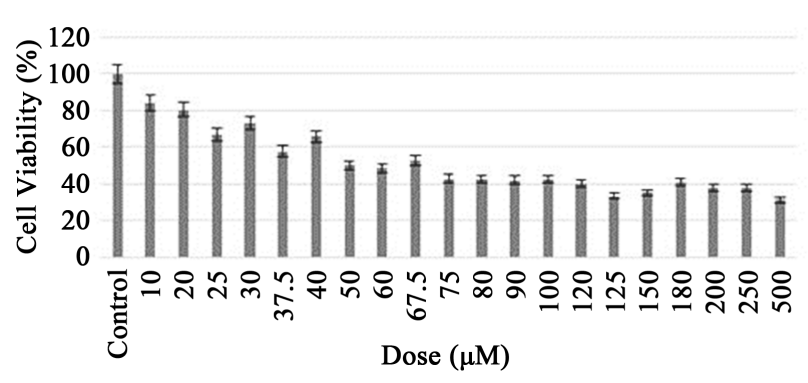

-SKBR3

(b)

Figure 1. (a) MTT Assay results for TMZ in MCF-7 cellline. According to assay results for MCF-7, the $\mathrm{IC}_{50}$ value was chosen $40 \mu \mathrm{M}$; (b) MTT Assay results for TMZ in SKBR3 cellline. According to assay results for SKBR3, the $\mathrm{IC}_{50}$ value was chosen $50 \mu \mathrm{M}$.
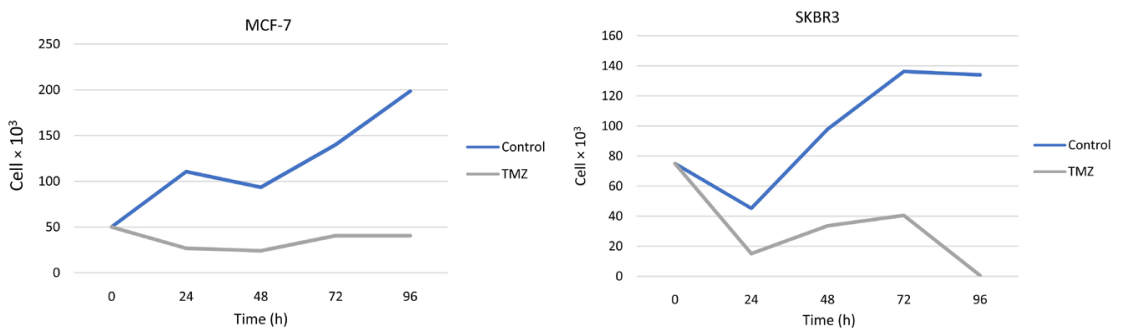

(a)

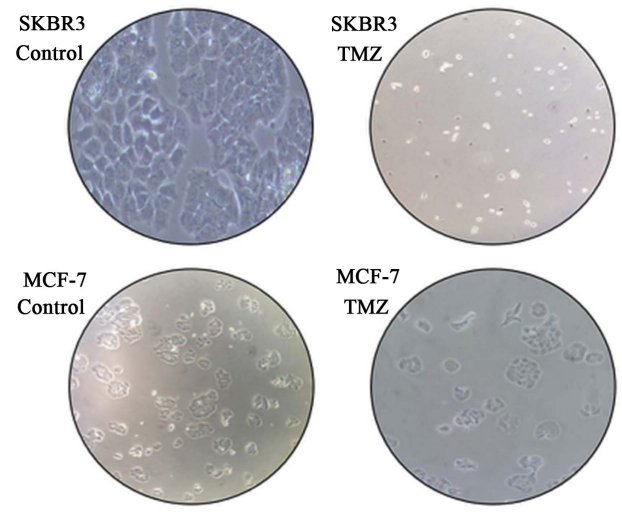

(b)

Figure 2. (a) Graphs of the results of time-dependent cell survival assay on MCF-7 and SKBR3 cell lines. According to trypan blue assay results, TMZ appears to be more cytotoxic for SKBR3 cell line (83.5\% kill rate for MCF-7 and 99\% kill rate for SKBR3 at the end of 96 hours); (b) Images of the control group cells and TMZ treated-cells at $96^{\text {th }}$ hour obtained from cell count performed in Trypan Blue Assay. 
was observed that it had a toxic effect at 48th hour, and increased cell viability at 72nd and 96th hours.

\subsubsection{Time-Dependent Survival Test Findings in SKBR3 Cell Line}

The raw data obtained as a result of 24, 48, 72 and 96-hour tests performed on SKBR3 cell line by applying $50 \mu \mathrm{M}$ drug dose we obtained from MTT Assay results were made a graph. The treated drug was observed to kill $83.5 \%$ of the seeded cells at 24th hour, as seen in Figure 2(a). It was observed that it continued this effect in the following hours, and at the end of 96 hours, $99 \%$ of the seeded cells died.

\subsection{Western Blot Assay}

\subsubsection{MGMT Gene Expression Levels in MCF-7 Cell Line}

Cell line western blot assay showed that expression level of MGMT protein was high before the TMZ treatment but decreased after the TMZ treatment.

\subsubsection{MGMT Gene Expression Levels in SKBR3 Cell Line}

As shown in Figure 3, cell line western blot assay showed that expression level of MGMT protein was high before the TMZ treatment but decreased after the TMZ treatment.

\subsection{High Resolution MGMT Promoter Methylation Assay}

\subsubsection{High-Resolution MGMT Promoter Methylation Assay Findings in MCF-7 Cell Line}

After bisulfite modification process, HRM (High Resolution Melting) process was performed in Real-Time PCR device (Agilent Technologies). Suitable PCR conditions for bisulfite-modified DNA samples (DNA samples with and without TMZ treatment) were prepared and PCR process was performed in Real-Time PCR device to compare high-resolution melting temperatures.

According to the results given in Table 2, MGMT gene promoter region in MCF-7 cell line was found to have a methylation level of about 30\% in control cells without TMZ treatment. In the group in which the TMZ treatment was made, the methylation level was found to be about $65 \%$.

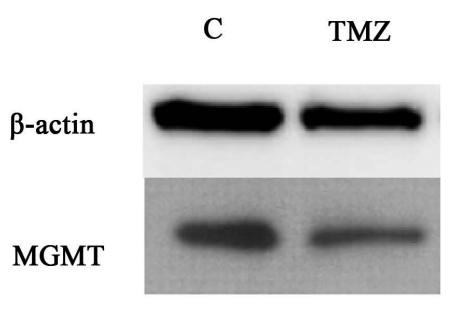

(a)

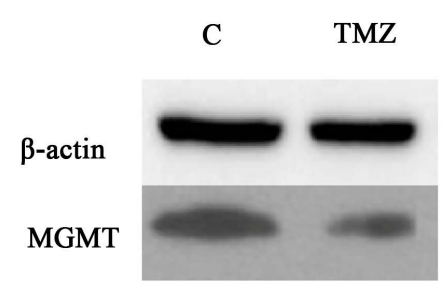

(b)

Figure 3. (a) MGMT protein levels after 24-h TMZ treatment in MCF-7 cells; (b) MGMT protein levels after 24-h TMZ treatment in SKBR3 cells. In both cell lines, MGMT protein levels decreased by TMZ treatment, but in MCF-7 cells, MGMT protein levels decrease less than SKBR3 cells, according to these results, TMZ treatment more effective on SKBR3 cells. C: Control cells; TMZ: Temozolomide-treated cells. 
Table 2. According to the high-resolution MGMT promoter methylation assays, MGMT gene promoter percentages on MCF-7 cell line subjected to TMZ treatment. (C: Control group; T: TMZ treated group). These results shows TMZ treatment increased methylation of MGMT gene promoter region.

\begin{tabular}{llllllllll}
\hline & \multicolumn{10}{c}{ Methylation \% } \\
\cline { 2 - 8 } & 0 & $0-25$ & 25 & $25-50$ & 50 & $50-75$ & 75 & $75-100$ & 100 \\
\hline (C) MCF-7 & & & & & & & & & \\
(T) MCF-7 & & & & & & & & & \\
\hline
\end{tabular}

\subsubsection{High-Resolution MGMT Promoter Methylation Assay Findings in SKBR3 Cell Line}

After bisulfite modification process, HRM process was performed in Real-Time PCR device (Agilent Technologies). Suitable PCR conditions for bisulfite-modified DNA samples (DNA samples with and without TMZ treatment) were prepared and PCR process was performed in Real-Time PCR device to compare high-resolution melting temperatures.

According to the results given in Table 3, MGMT gene promoter region in SKBR3 cell line was found to have a methylation level of about $28 \%$ in control cells without TMZ treatment. In the group in which the TMZ treatment was made, the methylation level was found to be about $80 \%$.

\section{Discussion}

This study, in which the effects of the TMZ which is an alkylating agent on MCF-7 cell line are examined, is the first study of the drug on breast cancer. The data obtained with MTT showed that TMZ did not reduce cell viability significantly at low doses, whereas it reduced the cell viability of $\mathrm{IC}_{50}$ value, which is 40 $\mu \mathrm{M}$ in MCF-7 cell line, by $49 \%$. In the time-dependent cell survival tests performed with different doses in SKBR3 cell line, a cytotoxicity of $83.5 \%$ was observed in the first 24 hours of treatment with TMZ and it was found that this ratio was $99 \%$ at the end of 96 hours.

A combined therapy in metastatic melanoma patients was tried as ipilimumab and TMZ. Ipilimumab was treated at a dose of $10 \mathrm{mg} / \mathrm{kg}$ and TMZ at 200 $\mathrm{mg} / \mathrm{m}^{2}$. In $15.6 \%$ of the patients, partial response was obtained whereas in $15.6 \%$ of the patients, complete response was obtained and no cytotoxic effect and death were observed during the study [16].

In one study, it was determined that $\mathrm{TMZ} \mathrm{IC}_{50}$ value varied on different glioblastoma cell lines (A172, LN229, SF268 and SK-N-SH) according to the cell lines. $\mathrm{IC}_{50}$ value remained below $50 \mu \mathrm{M}$ in A172 and LN229 glioblastoma cell lines. In SF268 and SK-N-SH cell lines; however, IC $_{50}$ value was above $100 \mu \mathrm{M}$ [15]. In MTT test, the dose-dependent study performed in our study, given the different characteristics of two different breast cancer cell lines, different $\mathrm{IC}_{50}$ values of TMZ are consistent with the studies in literature. MCF-7 and SKBR3 cell lines have different characteristics in terms of genes such as ER- $\alpha$ and P53. Considering this fact, it is thought that the reason why different doses are effective 
Table 3. According to the high-resolution MGMT promoter methylation assays, MGMT gene promoter percentages on SKBR3 cell line subjected to TMZ treatment. (C: Control group; T: TMZ treated group). These results shows TMZ treatment increased methylation of MGMT gene promoter region.

\begin{tabular}{|c|c|c|c|c|c|c|c|c|c|}
\hline & \multicolumn{9}{|c|}{ Methylation \% } \\
\hline & 0 & $0-25$ & 25 & $25-50$ & 50 & $50-75$ & 75 & $75-100$ & 100 \\
\hline \multicolumn{10}{|l|}{ (C) SKBR3 } \\
\hline (T) SKBR3 & & & & & & & & & \\
\hline
\end{tabular}

in different cell lines is related to expression levels of the proteins seen in cell lines and the correlative expression of different proteins.

In studies performed in patients with glioblastoma; the survival rates of patients who received radiotherapy among 573 patients were 12.1 months and this rate was 14.6 months in patients receiving TMZ treatment in addition to radiotherapy. The two-year survival rate was observed to be $26.5 \%$ in treatment with radiotherapy and TMZ, and $10.4 \%$ in radiotherapy alone [14]. In another study with breast cancer demonstrates that survival rates of MCF-7 cells, which has $\mathrm{ER}^{+}$character, decreased to $52 \%$ exposed to $644 \mu \mathrm{M}$ TMZ treatment for 4 days [17].

When the results of time-dependent cell survival tests are examined, it was seen that MCF-7 cell line was resistant to the $40 \mu \mathrm{M}$ TMZ treatment after 24 hours, and therefore the TMZ was not fully effective. In the time-dependent results on SKBR3 cell line, TMZ was found to be highly effective and $99 \%$ of the cells died after 96 hours due to its effect on the cells. This supports the thought that TMZ can be used as a single agent treatment in SKBR3 cell line. It is thought that patients with MCF-7 cell line characteristics (ER- $\alpha^{+}, \mathrm{P}^{+} 3^{+}$) TMZ is not effective as a single agent (ER and MGMT gene expressions are correlated [15] and these two genes are highly expressed in MCF-7 cells) and should be combined with different drugs. It is also thought that TMZ can be used as a single agent for patients with SKBR3 cell line characteristics (ER- $\alpha^{-}, \mathrm{P}^{-} 3^{-}$).

MGMT promoter methylation status is known to be the most important factor in the action mechanism of TMZ. In patients with glioblastoma multiforme (GB), particularly in groups with MGMT gene methylation, TMZ treatment was more effective, while response to the treatment was lower as the methylation rate decreased. The methylation of the MGMT promoter region is present in 35\% $45 \%$ (WHO III and IV) of malignant gliomas and approximately $80 \%$ of WHO grade-II gliomas. The mean survival time of patients with methylated MGMT promoter region was 21.7 months, while that of those with unmethylated MGMT promoter region was 12.7 months [18].

In the in vivo study performed on Glioblastoma xenograft mice, it was found that the methylation levels of MGMT promoter regions are reduced and MGMT protein expression is increased in xenograft mice treated with $100 \mu \mathrm{M} \mathrm{TMZ} \mathrm{[19].}$

In one study, methylation levels of MGMT gene promoter region in 10 pediatric glioblastoma patients were examined. Patients with methylated MGMT gene 
promoter region were more likely to respond to TMZ treatment and they had prolonged survival times while patients with unmethylated MGMT gene promoter region were less likely to respond to TMZ treatment and survival times were lower than those with the methylated gene promoter region [20].

In a study using methylation-specific PCR (MSP) technique on samples from 96 breast cancer patients, hypermethylation of MGMT gene promoter region was observed in $34.4 \%$ of the tumour tissues. In the same study, $\mathrm{ER}^{+}, \mathrm{PR}^{+}$and $\mathrm{C}$-erb- $2^{+}$conditions were found to have a significant relation to hypermethylation [21].

In another study, MGMT gene methylation was monitored in 84 triple-negative breast cancer patients treated with triple-negative breast cancer and alkylating agents. According to the results, MGMT gene was 58.3\% methylated, $27.4 \%$ unmethylated and $14.3 \%$ indeterminate in these patients [22].

When we examine the findings obtained after applying HRM-PCR method in our study, it was found that the methylation of MGMT gene promoter region is approximately 30\% in MCF-7 cells and that in the DNAs obtained after the administration of TMZ, the methylation rate of the promoter region is approximately $65 \%$. When the findings obtained from the study on SKBR3 cell line are examined, the methylation of MGMT gene promoter region in the DNAs of the control groups was found to be $28 \%$, whereas the methylation levels of MGMT gene promoter region in the DNAs of the TMZ treated groups was found to be about $80 \%$. It was observed that the treated TMZ increased MGMT promoter methylation rates in both cell lines.

When we compared the methylations of MGMT gene promoter region in MCF-7 and SKBR3 cell lines in our study, the lower survival rates in SKBR3 cell line are due to the higher rate of promoter methylation compared to the methylation of MGMT gene promoter region in the MCF-7 cell line.

In a study conducted in 2017, the findings of the study performed for the relation between P53 and MGMT genes on patients with metastatic pancreatic adenocarcinoma showed that MGMT expression was significantly lower in cell lines where P53 gene was mutated. It is observed that when P53 gene is positive, MGMT expression occurs at a lower level than P53 expression level, and when P53 gene is negative, MGMT gene expression was significantly lower [23].

TMZ cytotoxicity depends on the relation between $\mathrm{O}^{6}$-methylguanine formation and repair rates MGMT is expressed at different levels in different tissues [24] [25]. When comparing normal human breast epithelial cells (MCF10A) and human breast cancer cell lines (MCF-7, SKBR3, MDA-MB-468, HTB128, BT474, HCC38 and ZR75); MGMT expression levels are significantly greater in cancerous cells than in human normal breast epithelial cells. When MCF-7 and SKBR3 cell lines are compared among themselves; MGMT expression levels in MCF-7 cell line are higher than in SKBR3 cell line [26].

In a different study, ER- $\alpha^{+}$human breast cancer cell lines (MCF-7, T47D) and ER- $\alpha^{-}$human breast cancer cell lines (MDA-MB-468, MDA-MB-231) were used, and MGMT and ER- $\alpha$ proteins in breast cancer cells were found to be specifi- 
cally associated with immunoprecipitation. In addition, it was shown that silencing of MGMT gene expression leads to a decrease in both MGMT and ER- $\alpha$ protein levels. MGMT and ER- $\alpha$ proteins exist as a complex and are co-targeted for ubiquitin conjugation followed by proteasomal degradation [27].

In the other study, changes in MGMT gene expression were observed on $\mathrm{ER}^{+}$ (MCF-7, T47D, ZR-75-1) and ER ${ }^{-}$(ZR-75-30, HCC 148, MDA-MB-468) breast cancer cell lines. In this study, it has been observed that TMZ treatment can reduce MGMT expression in MCF-7 cells by 30\%. It was observed that TMZ reduced the activity of MGMT protein by $90 \%$. In addition, when MCF-7 cells were exposed to TMZ for 4 days, MGMT expression was inhibited by TMZ [17].

P53 gene is wild type in MCF-7 cell line. When compared with the findings of previous studies in patients with metastatic pancreatic adenocarcinoma [18]; MGMT gene, which is associated with the expression of P53 gene in MCF-7 cell line, is thought to cause resistance to TMZ due to its promoter methylation levels. SKBR3 cell line has a homozygous mutant character for P53 gene in terms of its general features and when the results of our study are compared with the results in the literature, it is seen that MGMT gene expression is significantly lower and that TMZ treatment is effective on the cell line.

As a result of TMZ therapy, resistancetodrugwasobserved in MCF-7 cells. The lack of resistance to TMZ in SKBR3 cell line and the higher activity of the TMZ compared to MCF-7 is thought to be due to the low MGMT expression levels in SKBR3.

SKBR3 cell line used in our study is an ER- $\alpha^{-}$cell line in terms of characteristics. When compared to other studies [17] [19] in which the relation between ER- $\alpha$ and MGMT gene is revealed, the low expression of MGMT gene expression in SKBR3 cell line is seen to correlate with a low ER- $\alpha$ expression level. As a result of this characteristic of SKBR3 cell line, it is thought that the absence of ER- $\alpha$ expression leads to a low level of MGMT expression and therefore, a positive effect of TMZ treatment. Due to the high expression level of ER- $\alpha$, a characteristic of MCF-7 cell line, it is thought that toxic effect of TMZ decreases and this is another cause of resistance to TMZ.

In preclinical studies, TMZ is seen to block G2/M phase of cell cycle in glioma cells and inhibits the cell development depending on the dose if it is treated concurrently with radiotherapy in glioblastoma cell line [28]. When we take into consideration the data we have obtained from our work, it is thought that the treatment of TMZ to MCF-7 cell line is not sufficient to block G2/M phase. It is thought that the formation of MGMT protein expression leads to a decrease in the TMZ activity as the cell line is a wild type of P53 and the methylation of MGMT gene promoter region is lower than SKBR3 cell line depending thereon. However, the increase observed in cell survival in time-dependent tests suggests that in MCF-7 cell line, TMZ is unable to block G2/M phase of the cell cycle but develops a resistance mechanism to the drug with different protein expressions. In SKBR3 cell line, it is thought that the TMZ can easily block G2/M phase with the condition of P53 gene having a homozygous mutant characteristic and high 
methylation of MGMT gene promoter region which is known to be associated with this gene, leading to a decreased expression.

\section{Conclusion}

When we compared the study results and the literature briefly, the methylation levels of MGMT gene promoter region for MCF-7 cell line restricted the use of TMZ as a single agent. At the same time, when the interaction of characteristics of the cell line with MGMT gene was examined, it was observed that the effectiveness of the drug was low in the time and dose dependent survival tests performed with TMZ treatment. Using the same parameters, it was observed that TMZ effect was higher on SKBR3 cell line. Therefore, it is seen that TMZ can be used as a combined treatment in MCF-7 cell line rather than as a single agent. In addition, TMZ can be used as a single agent in SKBR3 cell line. These studies show that these findings should be supported by in vitro and in vivo studies.

\section{Acknowledgements}

This study was supported by Scientific and Technological Research Council of Turkey (TUBITAK), "2209/A-University Students Research Projects Support Program” (Grant No. 1919B011601865).

\section{Conflicts of Interest}

We declare that there is no conflict of interest in this work.

\section{References}

[1] Siegel, R.L., Miller, K.D. and Jemal, A. (2017). Cancer Statistics, 2017. CA: A Cancer Journal for Clinicians, 67, 7-30. https://doi.org/10.3322/caac.21387

[2] Schüler-Toprak, S., Treeck, O. and Ortmann, O. (2017) Human Chorionic Gonadotropin and Breast Cancer. International Journal of Molecular Sciences, 18, 1587. https://doi.org/10.3390/ijms18071587

[3] Gradishar, W.J. (2012) Taxanes for the Treatment of Metastatic Breast Cancer. Breast Cancer. Basic and Clinical Research, 6, 159-171. https://doi.org/10.4137/BCBCR.S8205

[4] Kaçak, S., Çelik, L., Özbaş, S., Dizbay, S.S., Tükün, A. and Yalçın, B. (2011) Risk Factors in Breast Cancer, Risk Assessment and Prevention: Istanbul Consensus Meeting Report. European Journal of Breast Health, 7, 47-67.

[5] Lim, D.H.K. and Maher, E.R. (2010) DNA Methylation: A Form of Epigenetic Control of Gene Expression. The Obstetrician \& Gynaecologist, 12, 37-42. https://doi.org/10.1576/toag.12.1.037.27556

[6] Wu, Y., Sarkissyan, M. and Vadgama, J.V. (2014) Epigenetics in Breast and Prostate Cancer. İn: Verma, M., Ed., Cancer Epigenetics: Risk Assessment, Diagnosis, Treatment, and Prognosis, Springer, New York, 425-466. https://doi.org/10.1007/978-1-4939-1804-1_23

[7] Eroglu, O., Baysak, M.E., Aras, B.D., Cilingir, O. and Artan, S. (2018) Detection of Promoter Hypermethylation of GSTP1 and CDH1 Genes and the Relationship of Histopathological Parameters of the Breast. $A B C R, 7,91-106$. 
https://doi.org/10.4236/abcr.2018.72006

[8] Li, F. and Yang, Z. (2016) O-6-Methylguanine-DNA Methyltransferase Gene Promoter Methylation and Lung Cancer Risk: A Meta-Analysis. Journal of Cancer Research and Therapeutics, 12, 233. https://doi.org/10.4103/0973-1482.200745

[9] Bozkurt, E., Atmaca, H. and Uzunoğlu, S. (2013) Multiple Drug Resistance in Glioblastoma. Genel Tip Derg., 23, 133-143.

[10] Dullea, A. and Marignol, L. (2016) MGMT Testing Allows for Personalised Therapy in the Temozolomide Era. Tumor Biology, 37, 87-96.

https://doi.org/10.1007/s13277-015-4240-2

[11] Ralhan, R. and Kaur, J. (2007) Alkylating Agents and Cancer Therapy. Expert Opinion on Therapeutic Patents, 17, 1061-1075. https://doi.org/10.1517/13543776.17.9.1061

[12] Hegi, M.E., Diserens, A.-C., Gorlia, T., Hamou, M.-F., de Tribolet, N., Weller, M. and Stupp, R. (2005) MGMT Gene Silencing and Benefit from Temozolomide in Glioblastoma. The New England Journal of Medicine, 352, 997-1003. https://doi.org/10.1056/NEJMoa043331

[13] Eroğlu, C., Soyuer, S., Yıldız, O.G., Özkan, M. and Menku, A. (2008) The Effect of Temozolomide as Consolidation Chemotherapy on Treatment Results of Glioblastoma Multiforme Patients Treated with Concomittant Radiotherapy and Temozolomide. UHOD, 18, 65-73.

[14] Stupp, R., Mason, W.P. and van den Bent, M.J. (2005) Radiotherapy plus Concomitant and Adjuvant Temozolomide for Glioblastoma. Oncology Times, 27, 15-16. https://doi.org/10.1097/01.COT.0000289242.47980.f9

[15] Perazzoli, G., Prados, J., Ortiz, R., Caba, O., Cabeza, L., Berdasco, M. and Melguizo, C. (2015) Temozolomide resistance in glioblastoma Cell Lines: Implication of MGMT, MMR, P-Glycoprotein and CD133 Expression. PLoS ONE, 10, e0140131. https://doi.org/10.1371/journal.pone.0140131

[16] Patel, S.P., Kim, D.W., Bassett, R.L., Cain, S., Washington, E., Hwu, W., Bedikian, A.Y., et al. (2017) A Phase II Study of Ipilimumab plus Temozolomide in Patients with Metastatic Melanoma. Cancer Immunology, Immunotherapy, 66, 1359-1366. https://doi.org/10.1007/s00262-017-2030-y

[17] Bobustuc, G.C., Kassam, A.B., Rovin, R.A., Jeudy, S., Smith, J.S., Isley, B., Konduri, S.D., et al. (2018) MGMT Inhibition in ER Positive Breast Cancer Leads to CDC2, TOP2A, AURKB, CDC20, KIF20A, Cyclin A2, Cyclin B2, Cyclin D1, ER $\alpha$ and Survivin Inhibition and Enhances Response to Temozolomide. Oncotarget, 9, 29727-29742. https://doi.org/10.18632/oncotarget.25696

[18] Thon, N., Kreth, S. and Kreth, F.W. (2013) Personalized Treatment Strategies in Glioblastoma: MGMT Promoter Methylation Status. OncoTargets and Therapy, 6, 1363-1372. https://doi.org/10.2147/OTT.S50208

[19] Kitange, G.J., Carlson, B.L., Schroeder, M.A., Grogan, P.T., Lamont, J.D., Decker, P. A., Sarkaria, J.N., et al. (2009) Induction of MGMT Expression Is Associated with Temozolomide Resistance in Glioblastoma Xenografts. Neuro-Oncology, 11, 281-291. https://doi.org/10.1215/15228517-2008-090

[20] Donson, A.M., Addo-Yobo, S.O., Handler, M.H., Gore, L. and Foreman, N.K. (2007) MGMT Promoter Methylation Correlates with Survival Benefit and Sensitivity to Temozolomide in Pediatric Glioblastoma. Pediatric Blood and Cancer, 48, 403-407. https://doi.org/10.1002/pbc.20803

[21] Eroğlu, O., Yıldız, M., Muhammedoğlu, A., Kavşut, G., Güvenir, E., Muratoğlu, B., et al. (2014) Association of DNA Methylation of P16 ${ }^{\mathrm{INK} 4 \mathrm{~A}}$ (CDKN2A) and $M G M T$ 
Genes and Histopathological Features of Breast Cancer. 3rd International Congress of the Molecular Biology Association of Turkey, Izmir, 10-12 September 2014, 110141.

[22] Fumagalli, C., Pruneri, G., Possanzini, P., Manzotti, M., Barile, M., Feroce, I., Barberis, M., et al. (2012) Methylation of $\mathrm{O}^{6}$-Methylguanine-DNA Methyltransferase (MGMT) Promoter Gene in Triple-Negative Breast Cancer Patients. Breast Cancer Research and Treatment, 134, 131-137. https://doi.org/10.1007/s10549-011-1945-9

[23] Vitellius, C., Eymerit-Morin, C., Luet, D., Fizanne, L., Foubert, F., Bertrais, S., Caroli-Bosc, F.X., et al. (2017) Relationship between the Expression of $\mathrm{O}^{6}$ Methylguanine-DNA Methyltransferase (MGMT) and p53, and the Clinical Response in Metastatic Pancreatic Adenocarcinoma Treated with FOLFIRINOX. Clinical Drug Investigation, 37, 669-677. https://doi.org/10.1007/s40261-017-0522-3

[24] Graziani, G., Faraoni, I., Grohmann, U., Bianchi, R., Binaglia, L., Margison, G.P., D’Atri, S., et al. (1995) O6-Alkylguanine-DNA Alkyltransferase Attenuates Triazene-Induced Cytotoxicity and Tumor Cell Immunogenicity in Murine L1210 Leukemia. Cancer Research, 55, 6231-6236.

[25] Stupp, R., Gander, M., Leyvraz, S. and Newlands, E. (2001) Current and Future Developments in the Use of Temozolomide for the Treatment of Braintumours. Lancet Oncology, 2, 552-560. https://doi.org/10.1016/S1470-2045(01)00489-2

[26] Bobustuc, G.C., Smith, J.S., Maddipatla, S., Jeudy, S., Limaye, A., Isley, B., Konduri, S.D., et al. (2012) MGMT Inhibition Restores ER $\alpha$ Functional Sensitivity to Anti-Estrogen Therapy. Molecular Medicine, 18, Article ID: 1806913.

[27] Parajpe, A., Bailey, N.I., Konduri, S., Bobustuc, G.C., Ali-Osman, F., Yusuf, M.A., et al. (2016) New Insights into Estrogenic Regulation of $\mathrm{O}^{6}$-Methylguanine DNAMethyltransferase (MGMT) in Human Breast Cancer Cells: Co-Degradation of ER- $\alpha$ and $M G M T$ Proteins by Fulvestrantor $\mathrm{O}^{6}$-Benzylguanine Indicates Fresh Avenues for the Rapy. Journal of Biomedical Research, 30, 393-410.

[28] Hirose, Y., Berger, M.S., Pieper, R.O. and Cells, T.H.G. (2001) P53 Effects Both the Duration of $G_{2} / M$ Arrest and the Fate of p53 Effects Both the Duration of $G_{2} / M$ Arrest and the Fate of Temozolomide-Treated Human Glioblastoma Cells. Cancer Research, 61, 1957-1963. 